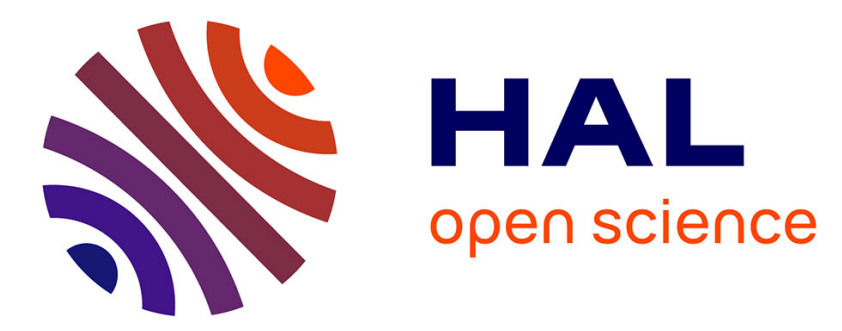

\title{
Electrochemical impedance spectroscopy characterization of conducting polymer/TiO2 nanotube array hybrid structures
}

\author{
Edgard Ngaboyamahina, Hubert Cachet, Alain Pailleret, Eliane Sutter
}

\section{To cite this version:}

Edgard Ngaboyamahina, Hubert Cachet, Alain Pailleret, Eliane Sutter. Electrochemical impedance spectroscopy characterization of conducting polymer/TiO2 nanotube array hybrid structures. Journal of electroanalytical chemistry and interfacial electrochemistry, 2015, 737, pp.37-45. 10.1016/j.jelechem.2014.09.029 . hal-01111490

\author{
HAL Id: hal-01111490 \\ https://hal.science/hal-01111490
}

Submitted on 2 Feb 2015

HAL is a multi-disciplinary open access archive for the deposit and dissemination of scientific research documents, whether they are published or not. The documents may come from teaching and research institutions in France or abroad, or from public or private research centers.
L'archive ouverte pluridisciplinaire HAL, est destinée au dépôt et à la diffusion de documents scientifiques de niveau recherche, publiés ou non, émanant des établissements d'enseignement et de recherche français ou étrangers, des laboratoires publics ou privés. 


\title{
Electrochemical impedance spectroscopy characterisation of conducting polymer / $\mathrm{TiO}_{2}$ nanotube array hybrid structures
}

\author{
E. Ngaboyamahina $^{\mathrm{a}, \mathrm{b}}$, H. Cachet ${ }^{\mathrm{a}, \mathrm{b}}$, A. Pailleret ${ }^{\mathrm{a}, \mathrm{b}}$, E.M.M. Sutter ${ }^{\mathrm{a}, \mathrm{b}, 1}$
}

a- CNRS, UMR 8235, Laboratoire Interfaces et Systèmes Electrochimiques, 4, place Jussieu, F-75005, Paris, France

b- Sorbonne Universités, UPMC Univ Paris 06, UMR 8235, LISE, 4, place Jussieu, F-75005, Paris, France

\begin{abstract}
The model suggested by Deslouis, Tribollet and co-workers in 1996 for describing the behaviour of polypyrrole deposited on a metallic substrate is here used for conducting polymers deposited on a nanostructured 3D semiconducting substrate. Impedance measurements were performed on a titanium oxide nanotubular array in the presence of two types of conducting polymers: polypyrrole and poly(3,4-ethylenedioxythiophene), highlighting the modification of the semiconducting properties of the substrate induced by the polymer deposition. The model is shown to be particularly well adapted for the PEDOT/ $\mathrm{TiO}_{2}$ hybrid structure, providing a valuable tool for characterizing the interaction between the conducting polymer and the semiconducting substrate.
\end{abstract}

Keywords: EIS, titanium oxide, nanotube array, polypyrrole, PEDOT

\section{Introduction}

Electronically Conducting Polymers (ECPs) are materials of increasing interest for application in fields such as supercapacitors, electrochromic devices, biosensors, electrocatalysts [1-10]. ECPs have been widely studied when deposited on usual electrode materials with metallic behaviours (platinum, gold, glassy carbon....) and electrochemical impedance spectroscopy (EIS) has been shown to be a convenient method for investigating the transport properties of these mixed ionic/electronic conductors [2,4,5,11-21]. Several

1 Corresponding author :

Email : eliane.sutter@upmc.fr

Phone : +33 (0) 144274168 
models have been suggested for describing the behaviour of ECPs on platinum. A complete model has been first suggested by Vorotyntsev et al [12] for a metal/ECP film/electrolyte system, taking into account the fluxes of electronic and ionic species at the different interfaces and in the polymeric film. Later on, Deslouis and co-workers [13, 14] applied this model on conducting polymer films under different boundary conditions (electrolyte/film/electrolyte, metal/film/metal and metal/film/electrolyte) and determined interfacial and transport parameters in the case of a polypyrrole film on a flat platinum electrode in different electrolytes. At last fine theoretical works were developed by Vorotyntsev et al [15-17] taking into account both the capacitive charging effects and the mixed electron-ion exchange across the film/solution interface.

Attempts to deposit ECP films on a nanostructured 3D substrate have been recently described [18-30]. For instance, deposition of PPy or PEDOT on titanium oxide nanotube arrays $\left(\mathrm{TiO}_{2}\right.$ NTAs) is expected to produce innovative 3D junctions with interesting characteristics and performances for applications in the fields of energy storage, photoelectric devices or solar cells $[22,29]$. Due to the semiconducting properties of $\mathrm{TiO}_{2}$, the rate of polymerization of the monomer has been shown to be enhanced by light excitation in the anodic potential range (electrophotopolymerization) [26,28,30,31].

The present paper shows preliminary results with the aim of verifying if the approximate theoretical model proposed in Ref. [14] can be extended to the case of an ECP film deposited on a semiconducting nanostructured substrate. It has been shown [30] that electrochemical or photoelectrochemical deposition of $\mathrm{PPy}$ on $\mathrm{TiO}_{2}-\mathrm{NTAs}$ provides an electroactive hybrid structure, but that the level of electroactivity depends on the electrolyte used during the deposition step, on the anodic potential and on the illumination conditions. EIS appears to be a convenient method for estimating the electronic and ionic conductivities of the hybrid structure, yet for need of comparison a single model is likely to be used, whatever the conditions of ECP formation. Since the model of ref [14] allows taking separately into account the contribution of diffusion-migration of ionic and electronic charge carriers inside the film, and charge transfer across substrate/ polymer and polymer/electrolyte interfaces, we will focus in this work on the modification of the conducting properties of the substrate in the presence of a PPy and of a PEDOT film. The model will be used to compare the behaviours of hybrid $\mathrm{PPy} / \mathrm{TiO}_{2}$-NTA structures obtained under potential scan in two different electrolytes: sodium dodecylbenzenesulfonate (SDBS) in which PPy film is mainly a 
cation exchanger and lithium perchlorate in which PPy behaves like an anion exchanger film [32]. A particular emphasis is also placed on the role of UV light illumination during the electrochemical generation of PPy, since it has been shown that photoelectrodeposited films often leads to hybrid structures with higher conductivity $[26,28]$. Since previous studies [10, 18,29] have shown the higher stability of PEDOT in comparison with PPy, the behaviour of a PEDOT-TiO 2 structure will also be investigated in $\mathrm{LiClO}_{4}$ to check if the model suggested in [14] for PPy deposit is also valid for a PEDOT film photoelectrodeposited from an acetonitrile solution. The modification of the semiconducting characteristics of $\mathrm{TiO}_{2} \mathrm{NTAs}$ (anatase type) covered with either a PPy or a PEDOT film will be discussed and compared in this work.

\section{Experimental part}

\subsection{Synthesis of $\mathrm{TiO}_{2}$-NTAs}

Prior to anodic oxidation, titanium discs (thickness $2 \mathrm{~mm}$, diameter $15 \mathrm{~mm}$, purity $99.6 \%$, purchased from Goodfellow) were polished with silicon carbide abrasive paper (P1200), and then rinsed first with ethanol, and finally in water in an ultrasonic bath. Thereafter the Ti discs were anodized in a $3 \mathrm{wt} \% \mathrm{NH}_{4} \mathrm{~F}$ solution in ethylene glycol containing 2 vol\% deionised water using a large area platinum counter electrode in a two electrode setup. The oxidation was performed at room temperature $\left(21^{\circ} \mathrm{C}\right)$ under a constant potential of $20 \mathrm{~V}$ vs. Pt for $45 \mathrm{~min}$.

Once anodized, samples were ultrasonically rinsed in ethanol and deionised water successively. At last, they were annealed at $525{ }^{\circ} \mathrm{C}$ for $2 \mathrm{~h}$ so as to convert the amorphous $\mathrm{TiO}_{2}$ structure into a well crystallized anatase structure which has been thoroughly characterized [33]. Anodization of the $\mathrm{Ti}$ substrate led to dense and homogeneous $\mathrm{TiO}_{2}-$ NTAs. Raman spectrometry and XRD spectrometry showed that anatase was the only component of the layer. The tubes exhibited smooth walls and were highly-ordered and vertically oriented as it can be seen on the FEG-SEM pictures in inset of Fig 1 . In our case, the flat surface of the samples (working electrode) exposed to the electrolyte, i.e. the geometric surface, $S_{\text {geo }}$, equals $0.78 \mathrm{~cm}^{2}$. The internal and external radii of the nanotubes, are 21 and $31 \mathrm{~nm}$ respectively, the length is about $960 \mathrm{~nm}$ and the mean thickness of the walls about $10 \mathrm{~nm}$. 


\subsection{Electropolymerization of the monomers}

Fresh aqueous solutions of $0.1 \mathrm{M}$ distilled pyrrole monomer were prepared in different 0.1 M supporting electrolytes, either sodium dodecylbenzenesulfonate (SDBS) or lithium perchlorate $\left(\mathrm{LiClO}_{4}\right)$. The resulting polymers are respectively named either PPy(DBS) or $\mathrm{PPy}\left(\mathrm{ClO}_{4}\right)$. In the case of SDBS, the selected concentration value is much higher than the value of critical micellar concentration (CMC), which has been shown to be about $1.5 \mathrm{mM}$ in aqueous solution [34]. It has to be underlined that PPy deposition performed in similar conditions led to poorly adherent layers on compact titanium oxide samples, whereas the layer on nanostructured oxide layers showed good adherence.

Poly(3,4-ethylenedioxythiophene) (PEDOT) films were obtained from 0.05 M EDOT solutions in as-received acetonitrile solution containing $0.1 \mathrm{M} \mathrm{LiClO}_{4}$. Electropolymerization was carried out on a $\mathrm{TiO}_{2}$-NTA used as a working electrode by cyclic voltammetry between 0.7 and $1.4 \mathrm{~V}$ vs. Ag wire, at a scan rate of $100 \mathrm{mV} / \mathrm{s}$, and at room temperature $\left(21^{\circ} \mathrm{C}\right)$. All the polymer layers studied in this work were obtained after 40 consecutive scans. For UV assisted electropolymerization, i.e. photoelectropolymerization experiments the samples were illuminated with a 125 W mercury vapour lamp (HPR 125 W (Philips), wavelength range: 300-400 nm). The UV light source was placed at a distance of $25 \mathrm{~cm}$ from the working electrode and the UV beam was perpendicular to the working electrode surface.

\subsection{Characterization}

The morphology of the resulting hybrid structures was studied by FEG-SEM (Zeiss, Ultra 55) (Fig 1 a-c). A Jobin-Yvon (Labram 010) Raman spectrophotometer equipped with a He-Ne laser (wavelength $632.8 \mathrm{~nm}$ ) was used to confirm the structure of the polymer films as well as their oxidation state. The thickness of the deposits was difficult to estimate precisely with SEM method but was estimated to be around 1 to $2 \mu \mathrm{m}$ in the different cases.

From the deposition charges, the average thickness estimated is also very approximate, since the deposit is not uniform, the coverage rate is uncertain, and the current measured under light exposure is partially due to water oxidation. Nevertheless, a very rough estimation taking a deposition area of $0.78 \mathrm{~cm}^{2}$, a density of 1.54 for the PPy film, would lead to a thickness of $0.4 \mu \mathrm{m}$ and $1.4 \mu \mathrm{m}$ in $\mathrm{LiClO}_{4}$, respectively in the dark and under UV light. In the same way, the thickness in SDBS would be close to $0.5 \mu \mathrm{m}$ under UV light, and negligible in the dark. 
Electrochemical characterization of the polymer films obtained after 40 cycles was performed in the dark, in a three-electrode cell, performed in the same supporting electrolyte as that used for the syntheses but without Py or EDOT monomer. During characterization of the hybrid structure, the shape of the voltammogram changes in the course of cycling, reaching a steady response after a few cycles. For PPy deposits, all the potentials are referred to a saturated calomel reference electrode (SCE), whereas for PEDOT films, an Ag wire was used as reference. In a separate experiment, the potential of the pseudo-reference Ag in acetonitrile was measured against a SCE dipped in an aqueous solution, and we found $\mathrm{E}_{\mathrm{Ag}}=$ $-0.03 \mathrm{~V}$ /SCE. Thus all the potential values are given against the SCE throughout the manuscript. The counter-electrode was a platinum spiral wire. The electrochemical characterization was An electrochemical interface (Solartron SI 1287) and a frequency response analyzer (Solartron 1250) were used to perform electrochemical impedance spectroscopy (EIS). Measurements were performed at a potential value selected inside a potential range shown to encompass the oxidation/reduction (i.e. doping/undoping) process of the polymers. Thus the investigated potential range was between -1.0 and $0.5 \mathrm{~V}$ vs. SCE in the presence of PPy films and between $-0.4 \mathrm{~V}$ and $0.8 \mathrm{~V}$ vs SCE in the presence of PEDOT films. EIS measurements were performed sequentially starting from the cathodic potential range towards the anodic range by $100 \mathrm{mV}$ steps, over frequencies ranging from $10 \mathrm{kHz}$ to $0.1 \mathrm{~Hz}$, using a $10 \mathrm{mV}$ (peak to zero) sinusoidal potential modulation. The different impedance parameters involved in the selected EIS model were obtained by a regression procedure based on a simplex strategy using the software SIMAD developed in our laboratory. (See Appendix)

\section{Results and discussion}

\subsection{The EIS model}

For the determination of quantitative transport and interfacial parameters of $\mathrm{ECP} / \mathrm{TiO}_{2}$-NTAs hybrid structures, the theoretical expressions for the ac impedance were fitted to the experimental data. According to ref [14], the theoretical expressions of impedance $\mathrm{Z}$ for a PPy film on a metallic substrate are the following:

$$
Z=R_{s}+Z_{m e}
$$




$$
\text { With } Z_{m e}=\frac{Z_{e}}{1+j \omega C_{e} Z_{e}}+\frac{Z i}{1+j \omega C_{i} Z_{i}}+Z_{p}
$$

where $R_{s}$ is the electrolyte resistance, $Z_{e}$ is the impedance at the substrate/polymer interface characterized by transfer resistance $R_{e}$ and interfacial double layer capacitance $C_{e}, Z_{i}$ is the impedance at the polymer /electrolyte interface characterized by transfer resistance $R_{i}$ and interfacial double layer capacitance $C_{i}$, and $Z_{p}$ is the impedance of the polymeric film with resistance $R_{p}$

Assuming that the diffusion coefficient of electrons $D_{e}$ is much higher than the diffusion coefficient of ions $D_{i}$ in the polymeric film, the expressions for $Z_{e}, Z_{i}$ and $Z_{p}$ are:

$$
\begin{aligned}
& Z_{e}=R_{e}+\frac{R_{p} D_{e}}{8 D_{i}}\left[\frac{\operatorname{coth} v}{v}-\frac{t h v}{v}\right] \\
& Z_{i}=R_{i}+\frac{R_{p} D_{e}}{8 D_{i}}\left[\frac{\operatorname{coth} v}{v}+\frac{t h v}{v}\right] \\
& Z_{p}=R_{p}+\frac{R_{p} D_{e}}{4 D_{i}}\left[\frac{t h v}{v}\right] \\
& v^{2}=\frac{j \omega d^{2}}{8 D_{i}} \quad \text { and } \tau=\frac{d^{2}}{8 D_{i}}
\end{aligned}
$$

$d$ is the polymer film thickness, $\omega$ is angular frequency , $\mathrm{j}=\sqrt{-1}$, and $\tau$ is a time constant related to ion diffusion in the film.

Due to the presence of a semiconducting substrate, an additional impedance $Z_{s c}$ has to be taken into account, with

$$
Z_{s c}=\frac{R_{s c}}{1+j \omega R_{s c} C_{s c}}
$$

where $C_{s c}$ is the space charge layer capacitance and $R_{s c}$ the internal resistance of the semiconductor. For most experiments $Z_{s c}$ and $Z_{m e}$ are in series (scheme (a) in Fig.2), corresponding to the case where the polymer film entirely covers the $\mathrm{TiO}_{2}$ substrate. In the case of SDBS the previous model does not allow representing the experimental data. Thus in order to obtain parameter values with physical meaning, it was necessary to add a resistance 
in series with $\mathrm{Z}_{\mathrm{sc}}$ (scheme (b) in Fig.2). This additional resistance $\mathrm{R}_{\mathrm{ad}}$ is attributed to a very thin poorly conductive PPy film deposited on some areas of the semiconductor which seem to be uncovered by SEM. Such PPy films were estimated by photocurrent measurements to be thinner than $50 \mathrm{~nm}$ [30]. $\mathrm{Z}_{\mathrm{me}}$ is the impedance of thicker PPy deposits, in parallel with the $\left(\mathrm{R}_{\mathrm{ad}}, \mathrm{Z}_{\mathrm{sc}}\right)$ branch, and is defined by equation [2].

According to [14] the resistance $R_{\text {inf }}$ in parallel with $Z_{s c}$ and $Z_{m e}$ in scheme (a) is assumed to account for a non-ideally blocking film/electrolyte interface with an eventual faradaic process. Such a parallel resistance is not necessary in scheme (b).

The adjustable parameters contained in equations (1) to (7) are:

$\tau, R_{s}, R_{e}, R_{i}, R_{p}, C_{e}, C_{i},\left(R_{p} D_{e}\right), R_{\text {inf }}\left(\right.$ or $\left.R_{a d}\right), D_{i}, R_{s c}, C_{s c}$.

The parameter $D_{e}$ cannot be obtained independently and only the product $\left(R_{p} D_{e}\right)$ is accessible. $D_{i}$ was fixed at values provided by different authors, and $R_{S}$ was known from preliminary experiments, limiting the number of adjustable parameters to 10.

From equations (5) and (6), the charging capacitance $C_{o}$ of the hybrid structure can then be estimated by the limit of the imaginary part of the film impedance $Z_{i}+Z_{e}$ in the lower limit of the frequency range:

Limit of $Z_{e}+Z_{i}=R_{e}+R_{i}+\frac{R_{p} D_{e}}{4 D_{i}}\left[\frac{\operatorname{coth} v}{v}\right]$ when $v \rightarrow 0$ is $R_{e}+R_{i}+\frac{R_{p} D_{e}}{4 D_{i}}\left[\frac{1}{v^{2}}\right]$ and the capacitance $C_{o}$ is given by equation (8):

$$
C_{o}=\frac{4 \mathrm{D}_{\mathrm{i}} \tau}{\mathrm{R}_{\mathrm{p}} \mathrm{D}_{\mathrm{e}}}
$$

$C_{0}$ would correspond to the vertical branch of the Nyquist diagram. It may be experimentally not observable if the parallel resistance $R_{\text {inf }}$ is too small ( $<10 \mathrm{k} \Omega$ in our experimental conditions) and/or the polymeric film presents some discontinuities due to not totally uniform deposition.

\subsection{Results and discussion}

In order to highlight the modifications of the characteristics of the semiconductor induced by the PPy deposit, $R_{S c}$ and $C_{s c}$ values determined for the hybrid structure are compared to those obtained for the unmodified electrode in the same electrolyte. 


\subsubsection{PPy in SDBS}

PPy layers obtained in SDBS under UV light after 40 cycles were characterized in the dark. During the scan towards more positive potentials, an oxidation peak observed at about $-0.2 \mathrm{~V}$ vs. SCE can be reasonably attributed to polymer oxidation (or doping). During the reverse scan a wide reduction peak with a maximum at $-0.7 \mathrm{~V}$ vs. SCE can be attributed to the electrochemical reduction of the doped polymer (undoping) (Fig 3A). During this reverse scan, one can predict that cations from the electrolyte, such as $\mathrm{Na}^{+}$and/or $\mathrm{H}^{+}$, are inserted in the polymeric layer to ensure electroneutrality, as a consequence of the irreversible entrapment of bulky dodecylbenzenesulfonate anions during the electrodeposition step of this polymer film. The inserted cations are expelled from the polymeric layer during the positive scan.

Deposition of PPy in SDBS at the concentration used in the present work (0.1M) have been shown to need a light source for deposition of a PPy seed layer [28-30], and the deposition can hardly be observed in the dark. Thus characterization by EIS was only performed on hybrid structures obtained under UV light. In Fig 3A an anodic charge of about $3 \mathrm{mC}$ can be estimated for a geometric surface of the electrode of $0.78 \mathrm{~cm}^{2}$. Comparatively deposition of PPy on a Pt electrode of same surface would lead to an anodic charge of $75 \mathrm{mC}$, as a consequence of a better conductivity of the substrate in the latter case. In [30], the percentage of uncovered (or poorly covered) surface was estimated to be almost 25\%, whatever the number of scans applied during PPy deposition, in the same conditions than in the present work. SEM observations qualitatively confirmed that some oxide zones were poorly covered by polymer.

Fig $4 \mathrm{~A}$ shows an impedance diagram in the Nyquist representation at $-0.1 \mathrm{~V}$ and $+0.2 \mathrm{~V}$ for the substrate and the $\mathrm{PPy} / \mathrm{TiO}_{2}$ hybrid structure obtained under illumination. Since the surface was only partially covered, scheme (b) was used for the fitting procedure, leading to a good agreement with the experimental data.

Examples of parameters obtained by the fitting procedure are shown in Table I at different potentials. Fig 5 represents the evolution of $R_{s c}$ (internal resistance of the semiconductor) as a function of applied potential in different electrolytes. For the substrate the increase in $R_{S C}$ when the potential increases is the usual behaviour of an n-type semiconductor and corresponds to progressive depletion of charges from the surface. For the hybrid structure obtained in SDBS, the same tendency is observed, yet with lower $R_{S c}$ values. The capacitance of the space charge layer $C_{s c}$ was also compared in a Mott Schottky representation $\left(1 /\left(C_{s c}\right)^{2}=\right.$ 
$\mathrm{f}(V)$ ) showing that the flat band potential is close to 0.1 V/SCE in SDBS, for the substrate and the hybrid structure (Fig 6). The smaller capacitance values in the presence of PPy can be attributed to a smaller "uncovered" surface in comparison with the reference electrode. (See model in section 3.1 and [30]).

Table I shows that the double layer capacitances $C_{i}$ and $C_{e}$ progressively increase when the potential gets more cathodic, simultaneously with the space charge capacitance.

According to equation (6), the diffusion length $d_{\text {diff }}$ could be estimated from determination of the time constant $\tau$, taking $\mathrm{D}_{\mathrm{i}}=1.6 \times 10^{-6} \mathrm{~cm}^{2} \mathrm{~s}^{-1}$ which corresponds to the diffusion coefficient of $\mathrm{Na}^{+}$in PPy given in ref [14]. Fig 7 shows that in SDBS, $d_{\text {diff }}$ varies between 0.1 and $2 \mu \mathrm{m}$, with the higher value in the cathodic range, at a potential close to $-0.4 \mathrm{~V}$, in agreement with the cathodic peak observed during potential scan in Fig 3A, due to $\mathrm{Na}^{+}$diffusion inside the polymer.

\subsubsection{PPy in $\mathrm{LiClO}_{4}$}

After synthesis of the organic polymer film inside $\mathrm{TiO}_{2}$-NTA in $\mathrm{LiClO}_{4}$ aqueous electrolyte, the electrochemical activity of the composite structure was characterized in the same supporting electrolyte using cyclic voltammetry. Whether the deposition was performed in the dark (Fig 3B) or under UV light (Fig 3C), a typical voltammogram corresponding to electrochemical doping/undoping of PPy was observed, yet with higher currents in the latter case.

Fig 4B and C compare impedance diagrams in the Nyquist representation at -0.1 and $0.2 \mathrm{~V}$ vs SCE respectively for the $\mathrm{PPy} / \mathrm{TiO}_{2}$ hybrid structures obtained in the dark and under illumination. Preliminary simulations of these diagrams using the same model as previously provided the best fits when $Z_{m e}$ and $Z_{s c}$ are in series, indicating that PPy is deposited over the whole surface of $\mathrm{TiO}_{2}$-NTAs. According to scheme (a) in Fig 2, adjusted parameters are given at some potential values in Tables 2 and 3. As previously the focus were put on the modification of $R_{s c}$ and $C_{s c}$ values in the presence of PPy and on the variation of the diffusion length as a function of applied potential.

Fig 5 compares the variation of $R_{s c}$ as a function of the potential in $\mathrm{LiClO}_{4}$ solution: in the presence of PPy, it appears that the values are lowered by a few orders of magnitude in comparison with the substrate, in the potential range positive to $-0.2 \mathrm{~V}$, i.e. in the potential range where doping occurs. The lowering is about 3 orders of magnitude when the polymer deposition was performed in the dark and up to 5 orders of magnitude when the deposition was performed under UV light, for the same number of cycles. In the potential range negative 
to $-0.2 \mathrm{~V}$ vs SCE, where de-doping of the polymer begins, the $R_{S c}$ values for the hybrid structure are similar to those observed for the substrate. It appears that when synthesized in $\mathrm{LiClO}_{4}$ the hybrid structure becomes electroactive in the potential range in which the polymer is doped (anodic range), and this is very different from the behaviour in SDBS.

The capacitance values $C_{s c}$ leading to the Mott Schottky representation of Fig 6, allowed to determine a flat band potential close to $-0.45 \mathrm{~V}$ vs SCE for the substrate in the $\mathrm{LiClO}_{4}$ solution. According to [35], the linear part of the curve (between $-0.45 \mathrm{~V}$ and $0 \mathrm{~V}$ ) describes the band bending variation which is supported by the tube walls under polarization, whereas the quasi plateau observed in the more anodic range, corresponds to the domain of complete depletion of the tube walls. In the present case due to the geometric parameters of the tubes, and the $10 \mathrm{~nm}$ thickness of the tube walls, the maximum width of the space charge layer supported by the tube walls would be $5 \mathrm{~nm}$. When PPy is deposited on the $\mathrm{TiO}_{2}-\mathrm{NTA}$ substrate, it has to be noted that the capacitance values are only slightly modified within the explored potential range. In Tables 2 and 3, $C_{s c}$ values decrease from about 440 to $32 \mu \mathrm{F}$ for the hybrid sample obtained in the dark and only from 44 to $14 \mu \mathrm{F}$ for the sample obtained under UV light, when applied potential is varied from $-0.5 \mathrm{~V}$ to $+0.5 \mathrm{~V}$ vs SCE. Such behaviour can be attributed to the presence of surface states at the interface between the semiconductor and the polymer, which lead to Fermi level pinning. This is more obvious when the hybrid was previously synthesized under UV light and is in close agreement with the ohmic junction described in ref [30] for the $\mathrm{PPy}^{-\mathrm{TiO}_{2}}$ hybrid structure.

It has to be noted from Tables 2 and 3 that the values of $R_{\text {inf }}$ are low, mainly in the anodic range, indicating that the interface between the hybrid structure and the electrolyte presents some non-ideal blocking behaviour. This could result from heterogeneous distribution of PPy islands giving rise to leakage currents between the islands.

The diffusion length $d_{\text {diff }}$ could be estimated from the determination of the time constant $\tau$, taking $D_{i}=4 \times 10^{-7} \mathrm{~cm}^{2} \mathrm{~s}^{-1}$ which corresponds to the diffusion coefficient of $\mathrm{ClO}_{4}{ }^{-}$inside PPy given in [14]. Fig 7 shows that in $\mathrm{LiClO}_{4}$ solution, $d_{\text {diff }}$ varies between 0.3 and $3 \mu \mathrm{m}$, with the higher values for the hybrid sample obtained under UV light. Since the thickness of the polymeric layer was estimated to be lower than $2 \mu \mathrm{m}$, we must admit that the value of 4 . $10^{-7} \mathrm{~cm}^{2} \mathrm{~s}^{-1}$ could be slightly overestimated. The variation of $d_{\text {diff }}$ with the applied potential is also surprising and can be attributed to two-dimensional transport of the anions, normal on one hand and radial between the islands on the other hand, as a consequence of inhomogeneity of the deposit. When the polymer was deposited in the dark, the diffusion 
length reaches a maximum at $0 \mathrm{~V}$, but at $0.4 \mathrm{~V}$ vs SCE when the deposit was performed under UV light, in agreement with the anodic peaks observed in the voltammogram of Fig $3 \mathrm{~B}$ and $\mathrm{C}$, due to doping of the polymer by $\mathrm{ClO}_{4}{ }^{-}$anions.

It is noticeable that in the present case we do not observe the usual three features characterizing ECP/metal structures, i.e. a high frequency loop, a Warburg domain in the intermediate frequency range, and a capacitive straight line in the low frequency range [12]. Moreover the overall impedance diagrams show a very flat shape which usually corresponds to heterogeneous surfaces with distributed properties over the surface. We suggest that the high frequency response is here spread over a wide frequency range, hiding the Warburg domain in the intermediate frequency range. From a physical point of view, it seem that in the present work the PPy layers are not continuous and therefore the model used in [14] for uniform polymeric films on flat metal substrates is formally applied in this case. It has to be noted that the diffusion parameters can be extracted with a good confidence interval.

\subsection{3. $\mathrm{PEDOT}$ in $\mathrm{LiClO}_{4}$}

Characterization of a hybrid structure made of PEDOT and $\mathrm{TiO}_{2}$-NTAs was performed in acetonitrile with $0.1 \mathrm{M} \mathrm{LiClO}_{4}$ as supporting electrolyte.

The voltammogram of Fig 3D shows the typical shape that is also observed on platinum (not shown) after 40 cycles, in the same experimental conditions.

Though many other, sometimes empirical, models can be found in the literature [18-21], the model suggested in Ref [14] for PPy, was also used in the present case, to interpret the experimental impedance diagrams obtained at different applied potentials. In Fig. 3D, the diagrams in the potential range between $-0.1 \mathrm{~V}$ and $+0.8 \mathrm{~V}$ vs SCE show the usual three features: a high frequency loop, a Warburg domain in the intermediate frequency range, and a capacitive straight line in the low frequency range. According to [12], the width of the Warburg domain depends on the ratio between the diffusion coefficients, $D_{i}$ and $D_{e}$, the former being generally smaller than the latter one. When $D_{e} / D_{i}$ increases, the vertical line is shifted towards lower frequencies and the Warburg region widens.

The adjusted parameters are reported in Table 4. The evolution of the parameters related to the semiconductor $\left(R_{S c}\right.$ and $C_{s c}$ ) is shown in Fig 8 and 9. Considering the evolution of $R_{s c}$ with potential, two domains are obvious: at $E>0 \mathrm{~V}$ vs SCE, $R_{S C}$ keeps a roughly constant value close to $40 \Omega$ followed by an increase when the potential reaches lower values. The low $R_{S C}$ values are thus observed in the domain of PEDOT doping, very similar to what was observed 
for the $\mathrm{PPy}\left(\mathrm{ClO}_{4}\right)$ deposits in Fig 5. The $1 /\left(C_{s c}\right)^{2}$ variations are reported in Fig 9 in a Mott Schottky representation for the uncovered $\mathrm{TiO}_{2}$-NTA substrate and the PEDOT covered substrate in acetonitrile solution containing $0.1 \mathrm{M} \mathrm{LiClO}_{4}$.

The substrate is characterized by a flat band potential close to $-0.25 \mathrm{~V}$ vs SCE, indicating a more positive value in comparison with the $\mathrm{LiClO}_{4}$ containing aqueous medium $(-0.45 \mathrm{~V} /$ SCE in Fig 6). Accordingly, acetonitrile [36] has been shown to be strongly adsorbed on anatase, thus modifying the conduction band level of the titanium oxide film. A negative shift is observed in the presence of a PEDOT layer, reaching -0.4 V/ SCE in Fig 9 after extrapolation of the capacitance values measured in the [0.2 to $0.6 \mathrm{~V}$ vs SCE] potential range. The overall shape of the Mott Schottky plot in the presence of PEDOT is very different from that of the reference sample, since a jump of $1 / C^{2}$ is observed between 0 and $0.2 \mathrm{~V}$ vs SCE). This can be attributed to electron trapping in the surface states of the semiconductor when the potential exceeds $0 \mathrm{~V}$. Since this potential range merges with the domain of PEDOT oxidation (doping), we suggest that the trapped electrons result from the oxidation of the polymer. On the contrary with what happens with PPy, the PEDOT coating allows the band bending inside the $\mathrm{TiO}_{2}$ substrate to be changed with the applied potential.

The evolution of the ionic diffusion length $d_{\text {diff }}$ as a function of the applied potential was estimated in Fig 10. As mentioned previously the diffusion length is limited by the thickness of the deposit and is related to the diffusion coefficient of $\mathrm{ClO}_{4}{ }^{-}$and to the diffusional time constant by relation (6). In the literature, the data provided for the diffusion coefficient of $\mathrm{ClO}_{4}{ }^{-}$in PEDOT varies by several orders of magnitude, from $10^{-5}$ to $10^{-9} \mathrm{~cm}^{2} \mathrm{~s}^{-1}$. The higher value which is similar to diffusion coefficients measured in aqueous solutions corresponds to highly wetted porous films [4], whereas the lower value would correspond to very compact films [18, 37]. It has also been shown that $D$ values increase with film thickness. For example, in Ref [18] the diffusion coefficient of $\mathrm{Cl}^{-}$in PEDOT has been reported to vary from $10^{-8}$ to $10^{-7} \mathrm{~cm}^{2} \mathrm{~s}^{-1}$ within the thickness range of 0.1 to $1.5 \mu \mathrm{m}$. Given the diffusional time constants between 0.2 and $0.6 \mathrm{~s}$ determined by the present model and given the thickness of the film (between 1 and $2 \mu \mathrm{m}$ ), a diffusion coefficient of $10^{-8} \mathrm{~cm}^{2} \mathrm{~s}^{-1}$ seems a reasonable value in the present work. Fig 10 shows a sharp increase of $d_{\text {diff }}$ when the potential reaches $0 \mathrm{~V}$ vs SCE, followed by a slight decrease in the more positive potential range, ranging from $2.1 \mu \mathrm{m}$ to 1.2 $\mu \mathrm{m}$ between 0 to $0.8 \mathrm{~V}$. It has to be noted that the $R_{\text {inf }}$ values in Table 4 are a few orders of magnitude higher than in the case of PPy in the presence of $\mathrm{LiClO}_{4}$ (Tables 2 and 3), 
indicating a more compact layer in the former case without any leakage in the film. Another significant difference between the two layers is the value of the resistance of the polymeric film (negligible in the case of PPy versus a few ohms in the case of PEDOT), indicating a lower diffusion coefficient for the electrons inside the PEDOT layer in comparison with the PPy layer. This remark is in agreement with the difference in shape of the EIS diagrams of Fig 4: the presence of a vertical line in the low frequency range for PEDOT (Fig 4D) indicates a $D_{e} / D_{i}$ ratio lower than for PPy (Fig $4 \mathrm{~B}$ and $\mathrm{C}$ ), in which the vertical line is likely to be shifted towards lower frequencies.

The calculation of $C_{o}$ from the adjusted parameters of Table 4 is reported in the last column, at different potentials, leading to a mean value of $1.9 \mathrm{mF}$, which is close to the capacitance value which can be estimated from the voltammogram in Fig 3D (about 3mF). This agreement validates the use of the model for describing the behaviour of the PEDOT-TiO ${ }_{2}$ NTA hybrid structure.

\section{Conclusion}

The present work shows that the model suggested by Deslouis, Tribollet and co-workers in the case of a PPy deposit on flat metals were used and applied for conducting polymers deposited on nanostructured titanium oxide. The model was successfully extended to PEDOT layers in non-aqueous solvents, indicating that the PEDOT layer on $\mathrm{TiO}_{2}-\mathrm{NTA}$ behaves like a continuous layer. The model was less efficient in the case of $\mathrm{PPy} / \mathrm{TiO}_{2}-\mathrm{NTA}$ hybrid structures, since the usual Warburg line could not be clearly observed in the impedance diagrams. This could be due to a heterogeneous PPy deposit which generates a high distribution of properties at the surface of the hybrid structure. Nevertheless the samples studied in this work were not optimized for reaching the highest yield of charge storage or the highest capacitance, but were selected in order to prove that differences in the polymerisation conditions such as the nature of the solvent, the deposition rate or the nature of the polymer, induce different behaviours in the semiconducting oxide which can be highlighted by EIS. The model here used provides a valuable tool for characterizing the interaction between a ECP and a semiconducting substrate in order to further optimize the experimental parameters and reach the expected performances for such a hybrid structure. 


\section{Acknowledgements:}

Mrs F. Pillier is warmly acknowledged for her expertise in FEG-SEM experiments.

\section{Appendix}

Calculation of the impedance parameters by the regression procedure used by the SIMAD software and estimation of the confidence intervals.

Regression

Experimental spectra were fitted using a simplex procedure by means of an in-house software. The program minimized the $\chi^{2}$ function

$$
\chi^{2}=\sum_{i=1}^{n_{f}}\left[\left(\frac{\hat{Z}_{r}-Z_{r}}{\sigma}\right)^{2}+\left(\frac{\hat{Z}_{j}-Z_{j}}{\sigma}\right)^{2}\right]
$$

Where $n_{f}$ is the number of frequencies, the standard deviation for the measurement was assumed to be $\sigma=0.01|\mathrm{Z}|$ and the carat refers to the model value. The expression used for $\sigma$ corresponds to an assumption that the standard deviation for the impedance measurement was equal to one percent of the modulus.

For a complex regression, the fitting quality was determined by the standard deviation $\mathrm{q}$

$$
q=\sqrt{\frac{\chi^{2}}{v}}
$$

Where $v$ is the degree of freedom for the regression, i.e., the number of observations $2 n_{f}$ minus the number of adjustable parameters. A good fit should correspond to a value $q=1$. A smaller value of q means that a priori error was overestimated.

\section{Confidence intervals}

Confidence intervals for the fitted parameters were estimated empirically from the change in a single parameter value yielding an increase by a factor 1.5 of the standard deviation $\mathrm{q}$ characterizing the fit quality, the other parameters staying fixed to their optimal value. 


\section{REFERENCES}

[1] K. Shankar, G.K. Mor, M. Paulose, O.K. Varghese, C.A. Grimes, J. Non-Cryst. solids, 354 (2008) 2767-2771.

[2] M.R. Abidian, D.C. Martin, Biomaterials 29 (2008) 1273-1283.

[3] T.W. Zeng, H.H. Lo, Y.Y. Lin, Y.Y. Lin, C.W. Chen, W.F. Su, J. Sol. Energ. Mat. and Sol. C. 93 (2009) 952-957.

[4] P.M. Dziewonski, M. Grzeszczuk, Electrochim. Acta 55 (2010) 3336-3347.

[5] A. Faye, G. Dione, M.M. Dieng, J.J. Aaron, H. Cachet, C. Cachet, J. Appl. Electrochem. 40 (2010) 1925-1931.

[6] S.S. Li, C.P. Chang, C.C. Lin, Y.Y. Lin, Y.Y. Lin, C.H. Chang, J.R. Yang, M.W. Chu, C.W. Chen, J. Amer. Chem. Soc. 133 (2011) 11614-11620.

[7] J. Dehaudt, L. Beouch, S. Peralta, P.H. Aubert, C. Chevrot, F. Goubard, Thin Solid Films 519 (2011) 1876-1881.

[8] A. R. Goncalves, M.E. Ghica, C.M.A. Brett, Electrochim. Acta 56 (2011) 3685-3692.

[9] A. S. Karimullah, D.R.S. Cumming, M. Riehle, N. Gadegaard, Sensor Actuat. B 176 (2013) 667-674.

[10] G.P. Pandey, A.C. Rastogi, C R. Westgate,Z. Zhang, J.Pow. Sources 245 (2014) 857865.

[11] F. Fabregat-Santiago, G. Garcia-Belmonte, I. Mora-Sora, J. Bisquert, Phys. Chem Chem. Phys. 13 (2011) 9083-9118.

[12] M.A.Vorotyntsev, L.I. Daikhin, M.D. Levi, J. Electroanal. Chem. 364 (1994) 37-49.

[13] C. Deslouis, M.M. Musiani, B. Tribollet, M.A.Vorotyntsev, J. Electrochem. Soc. 142 (1995) 1902-1908.

[14] C. Deslouis, T.E. Moustafid, M.M. Musiani, B. Tribollet, Electrochim. Acta 41 (1996) 1343-1349.

[15] M.A. Vorotyntsev, J.P. Badiali, G. Inzelt, J. Electroanal. Chem. 472 (1999) 7-19.

[16] M.A. Vorotyntsev, C. Deslouis, M.M. Musiani, B. Tribollet, K. Aoki, Electrochim. Acta 44 (1999) 2105-2115.

[17] M.A. Vorotyntsev, Electrochim. Acta 47 (2002) 2071-2079.

[18] J. Bobacka, A. Lewenstam, A. Ivaska, J. Electroanal. Chem. 489 (2000) 17-27.

[19] G. Garcia-Belmonte, J. Bisquert Electrochim. Acta 47 (2002) 4263-4272.

[20] G.R. Hernandez-Labrado, R.E. Contreras-Donayre, J.E. Collazos-Castro, J.L. Polo, J. Electroanal. Chem. 659 (2011) 201-204. 
[21] L.F.Q.P. Marchesi, F.R. Simões, L.A. Pocrifka, E.C. Pereira, J. Phys. Chem.B 115 (2011) 9570-9575.

[22] Z. Zhang, Y. Yuan, L. Liang, Y. Cheng, H. Xu, G. Shi, L. Jin, Thin Solid Films, 516 (2008) 8663-8667.

[23] D. Kowalski, P. Schmuki, Chem. Commun. 46 (2010) 8585-8587.

[24] D. Kowalski, S. P. Albu, P. Schmuki, RSC Adv. 3 (2013) 2154-2157.

[25] D. Kowalski, A. Tighineanu, P. Schmuki , J.Mater. Chem. 21 (2011) 17909-17915.

[26] C. Janáky, N.R. de Tacconi, W. Chanmanee, K. Rajeshwar, J. Phys. Chem. C, 116 (2012) 19145-19155.

[27] D. Kowalski, D. Kim, P. Schmuki, Nano Today,8 (2013) 235-264.

[28] C. Janáky, W. Chanmanee, K. Rajeshwar, Electrochim. Acta 122 (2014) 303-309.

[29] C. Janáky, G. Bencsik, A. Rácz, C. Visy, Langmuir 26 (2010) 13697-13702.

[30] E. Ngaboyamahina, H. Cachet, A. Pailleret, E.M.M. Sutter, Electrochim. Acta 129 (2014) 211-221.

[31] F. Di Franco, P. Bochetta, M. Santamaria, F. Di Quarto, Electrochim. Acta 56 (2010) 737-744.

[32] C. Weidlich, K.M. Mangold, K. Juttner, Electrochim Acta, 50 (2005) 1547-1552.

[33] P. Pu, H. Cachet, E. Ngaboyamahina, E.M.M. Sutter, J. Solid State Electrochem. 17 (2013) 817-828.

[34] K. Naoi, Y. Oura, M. Maeda, S. Nakamura, Journal of The Electrochemical Society, 142 (1995) 417-422.

[35] P. Pu, H. Cachet, E.M.M. Sutter, Electrochim. Acta, 55 (2010) 5938-5946.

[36] A.J. Morris, G. J. Meyer, J. Phys. Chem. C 112 (2008) 18224-18231.

[37] X. Cui, D. C. Martin, Sensor Actuat. B 89 (2003) 92-102. 


\section{CAPTIONS}

Figure 1 FEG-SEM images of a $\mathrm{TiO}_{2}$-polymer junction after 40 scans

a) and b) $\mathrm{TiO}_{2}$ nanotubes partially filled by polypyrrole in SDBS, -top view (a) and sideview (b).

Inset of Fig a: FEG-SEM image of a pristine $\mathrm{TiO}_{2}-\mathrm{NTA}$

c) $\mathrm{TiO}_{2}$ nanotubes partially filled by PEDOT in $\mathrm{LiClO}_{4}$ and acetonitrile.

Figure 2 Equivalent circuits used to characterize the electrochemical behaviour (a) for hybrid structures $\mathrm{PPy}_{-} \mathrm{TiO}_{2}$ obtained in $\mathrm{LiClO}_{4}$ aqueous solution and $\mathrm{PEDOT}^{-\mathrm{TiO}_{2}}$ obtained in $\mathrm{LiClO}_{4}$ acetonitrile solution. (b) for hybrid structures $\mathrm{PPy}-\mathrm{TiO}_{2}$ obtained in SDBS aqueous solution.

Figure 3 Voltammograms for polymer/TiO 2 -NTA structures A): PPy deposited under UV in SDBS B) PPy deposited in the dark in $\mathrm{LiClO}_{4} \quad$ C) PPy deposited under $\mathrm{UV}$ in $\mathrm{LiClO}_{4} \quad$ D) PEDOT deposited in the dark in acetonitrile $+\mathrm{LiClO}_{4} . \quad \mathrm{v}=10 \mathrm{mV} / \mathrm{s}$ Polymer deposits were analysed after 40 cycles of potential scans.

Figure 4 Impedance diagrams and corresponding fitted curves in the oxidation potential range for polymer/TiO 2 -NTA structures A): PPy deposited under UV in SDBS B) PPy deposited in the dark in $\mathrm{LiClO}_{4}$ C) PPy deposited under UV in $\mathrm{LiClO}_{4}$ D) PEDOT deposited in the dark in acetonitrile $+\mathrm{LiClO}_{4}$.

Polymer deposits were analysed after 40 cycles of potential scans.

Figure 5 Variations of $R_{s c}$ with applied potential for $\mathrm{TiO}_{2}$ NTA (substrate) and for the PPy$\mathrm{TiO}_{2}$-NTA hybrid structures obtained in $\mathrm{LiClO}_{4}$ and SDBS solutions.

Figure 6 Variations of $\left(1 / \mathrm{C}_{\mathrm{sc}}\right)^{2}$ with applied potential for $\mathrm{TiO}_{2}$ NTA (substrate) and for the PPy-TiO $-\mathrm{NTA}$ hybrid structures obtained in $\mathrm{LiClO}_{4}$ and SDBS solutions.

Figure 7 Comparison between diffusion lengths with applied potential for $\mathrm{PPy}-\mathrm{TiO}_{2} \mathrm{NTA}$ hybrid structures obtained in SDBS and $\mathrm{LiClO}_{4}$ solutions. 
Figure 8 Evolution of Rsc as a function of applied potential for a $\mathrm{TiO}_{2}-\mathrm{NTA}$ substrate and the hybrid structure with PEDOT in $\mathrm{LiClO}_{4}$

Figure 9 Variation of $1 / \mathrm{C}^{2}$ as a function of applied potential for $\mathrm{TiO}_{2}-\mathrm{NTA}$ substrate and for the hybrid structure Pedot/TiO 2 - NTA in $\mathrm{LiClO}_{4}$

Figure 10 Diffusion length as a function of applied potential for a hybrid structure made of Pedot on $\mathrm{TiO}_{2}-\mathrm{NTA}$ in $\mathrm{LiClO}_{4}$ in the dark $\left(\mathrm{D}=10^{-8} \mathrm{~cm}^{2} \mathrm{~s}^{-1}\right)$ 


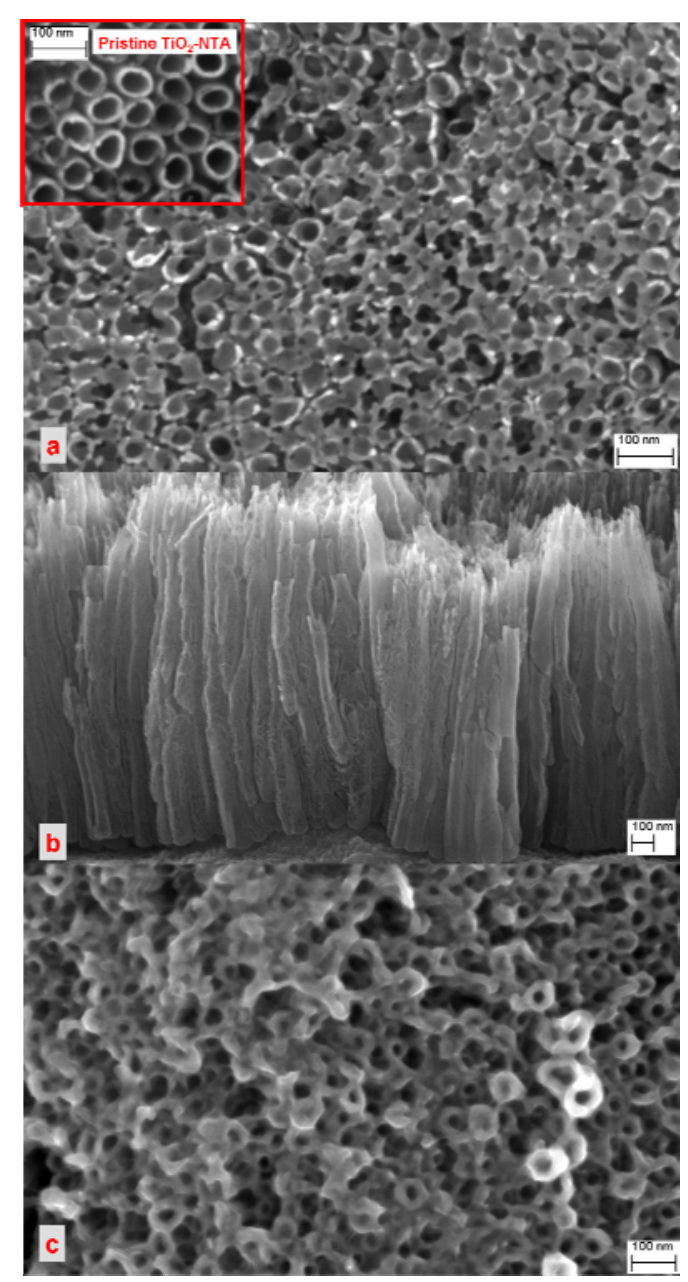

Figure 1 


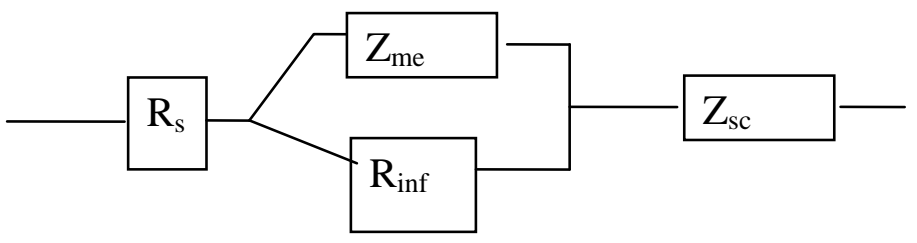

(a)

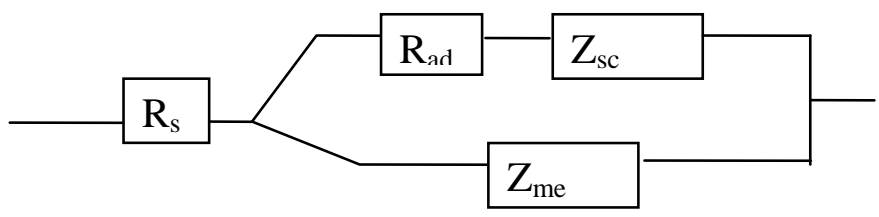

(b)

Figure 2 


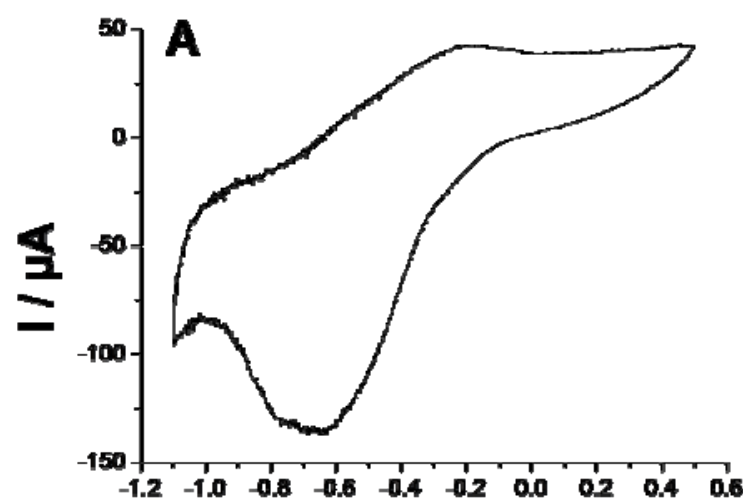

E IV (SCE)

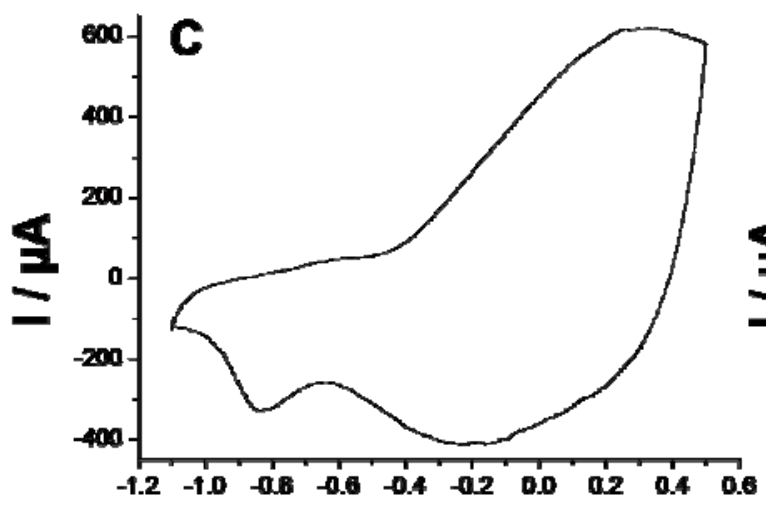

E IV (SCE)

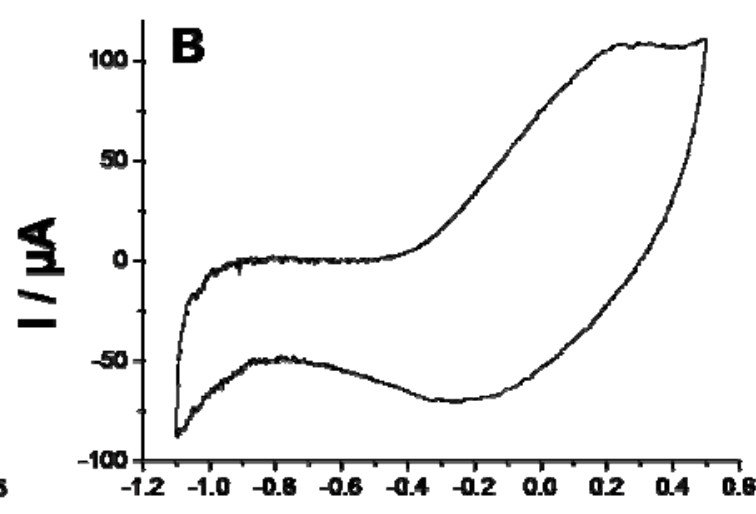

E IV (SCE)

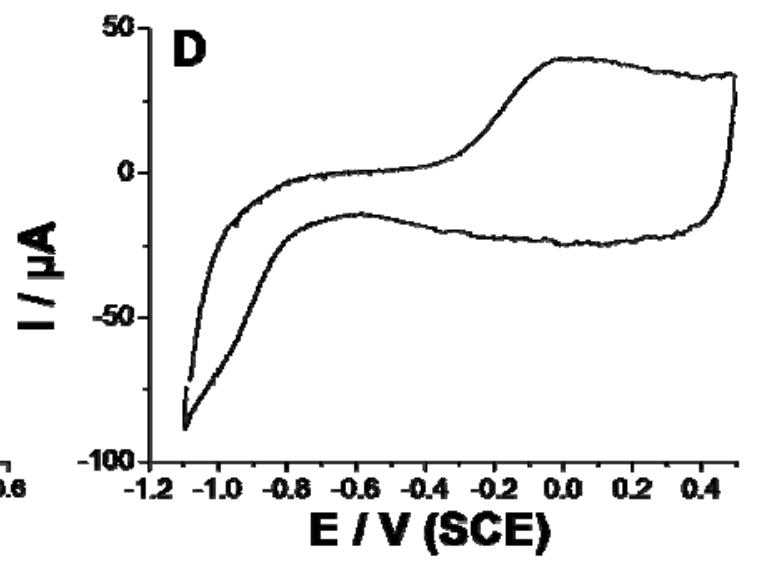

Figure 3 

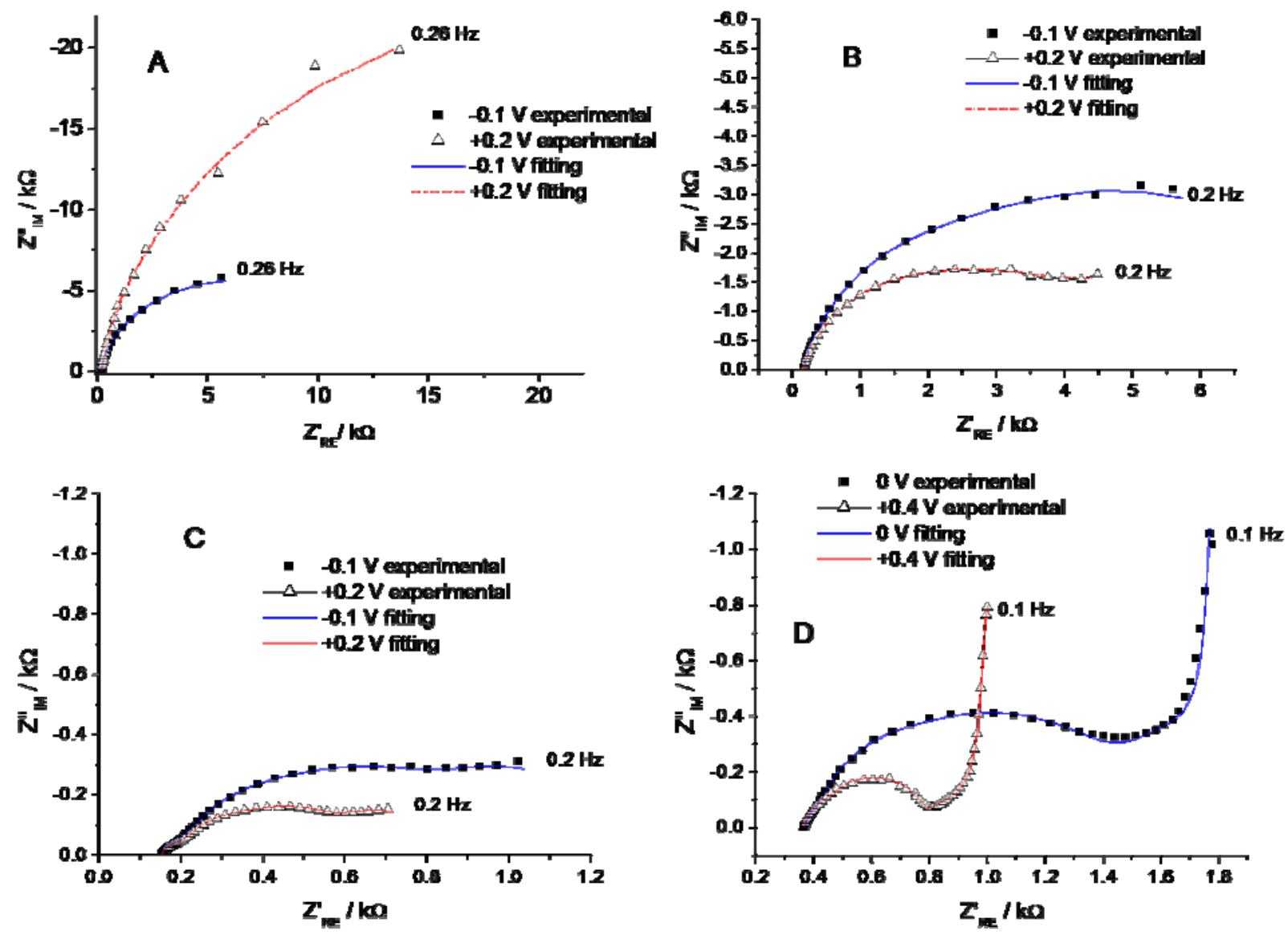

Figure 4 


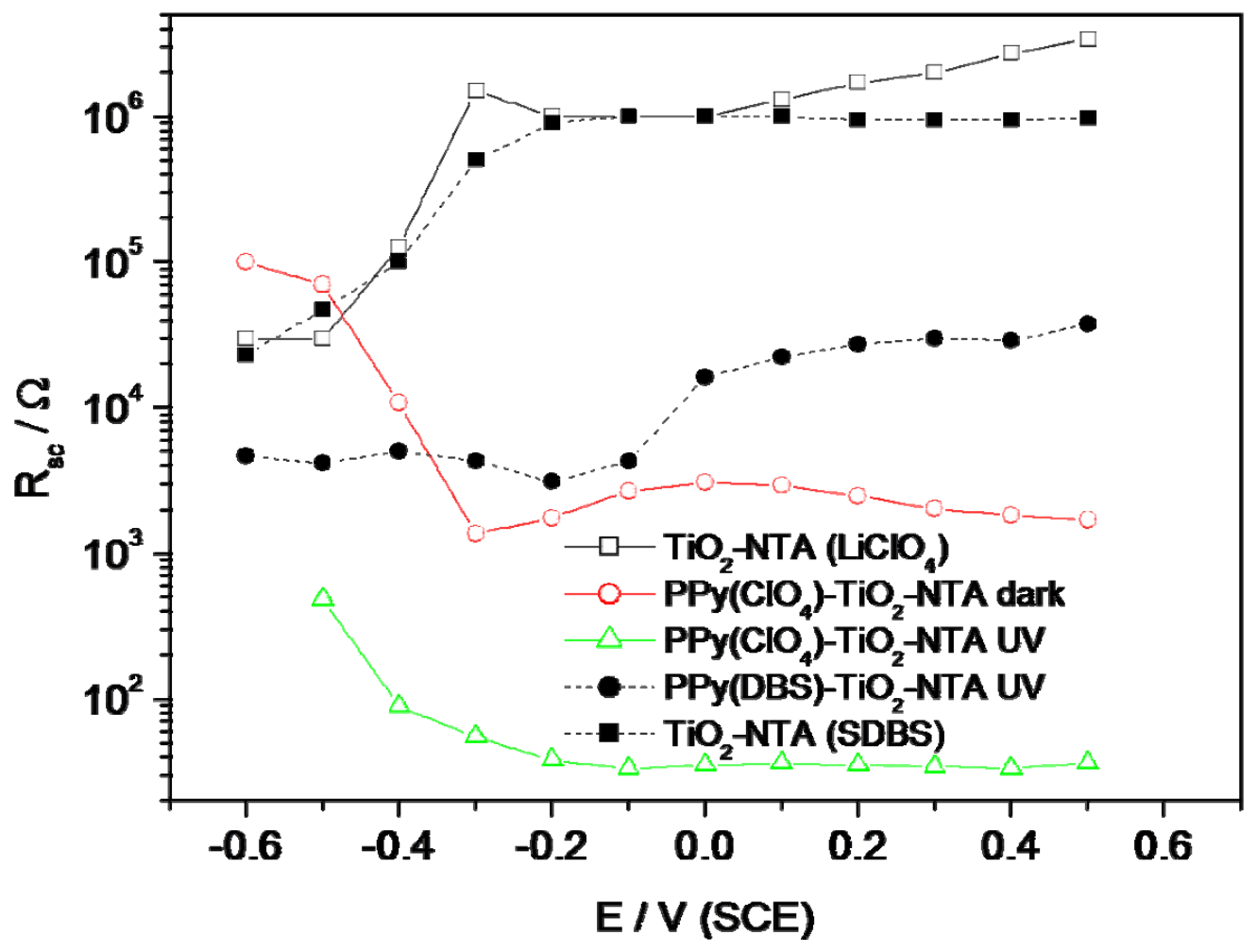

Figure 5 


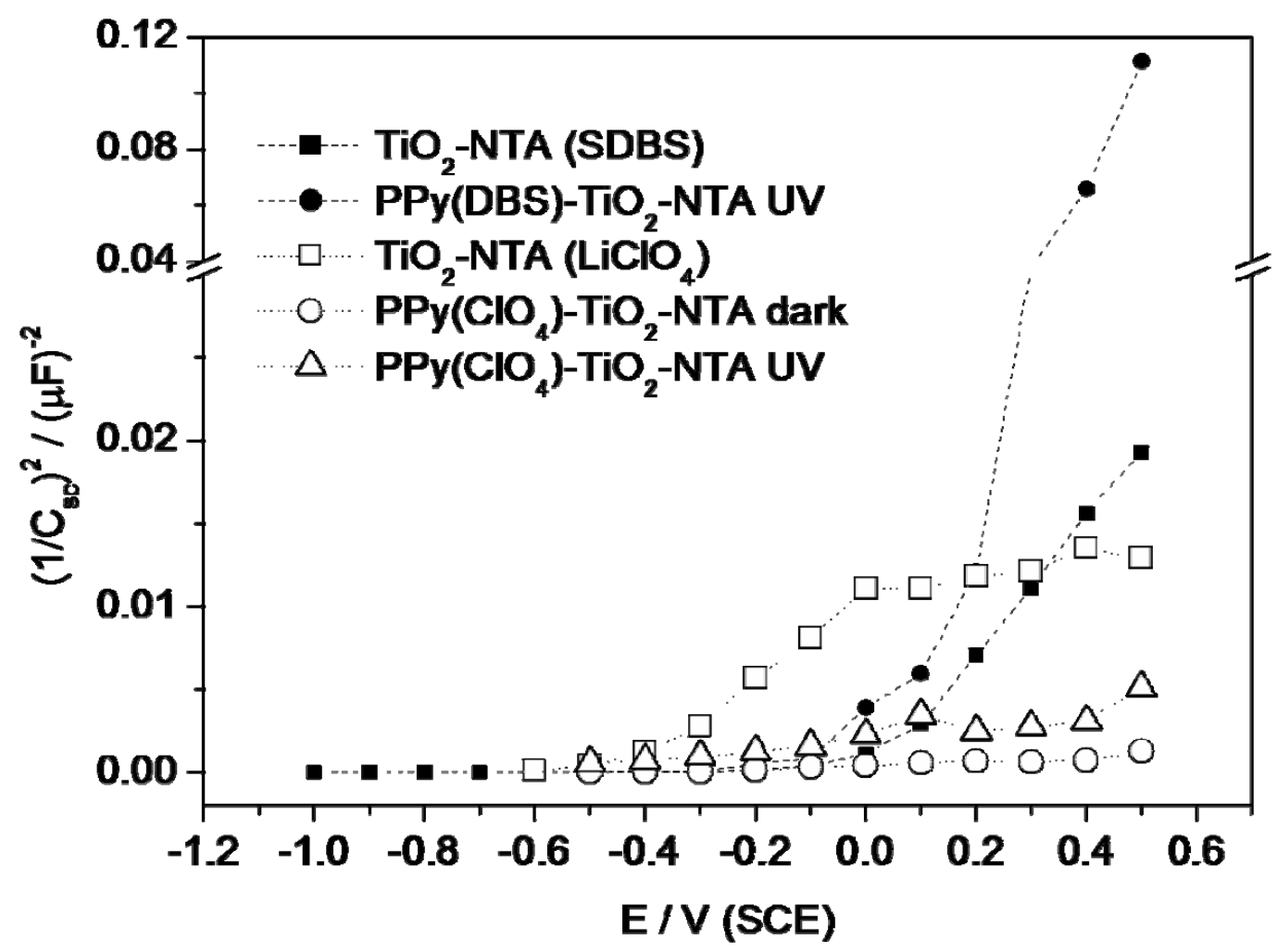

Figure 6 


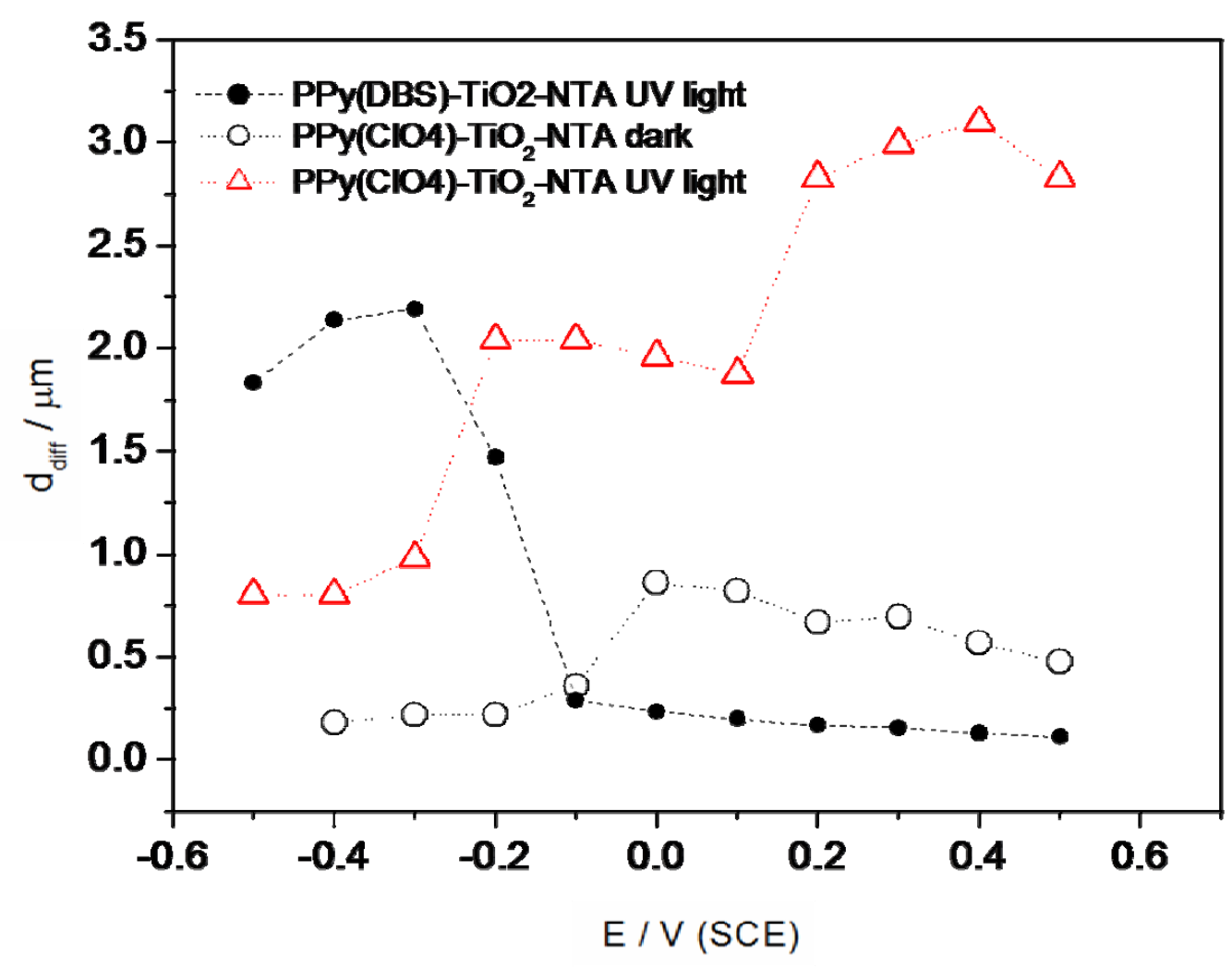

Figure 7 


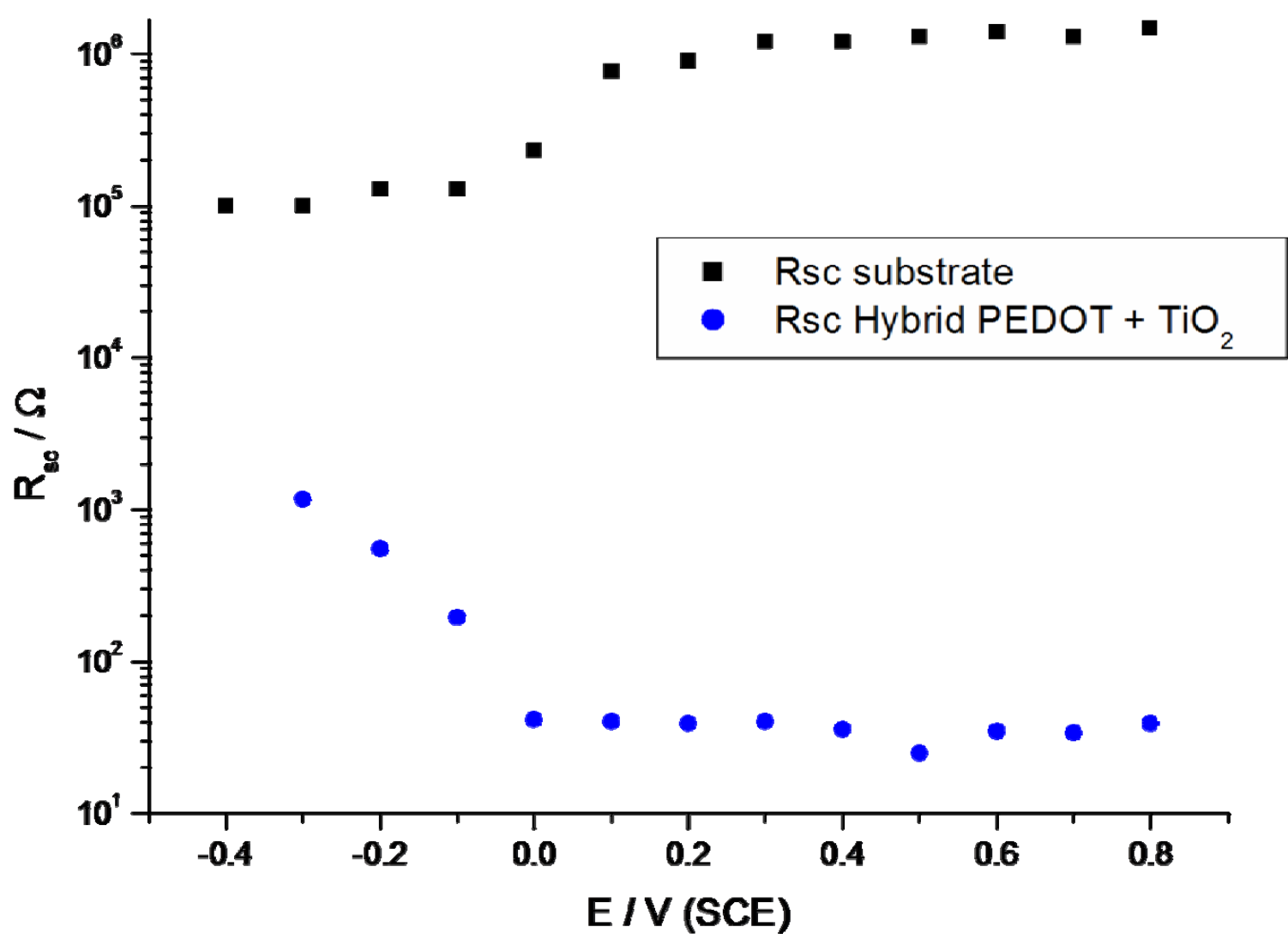

Figure 8 


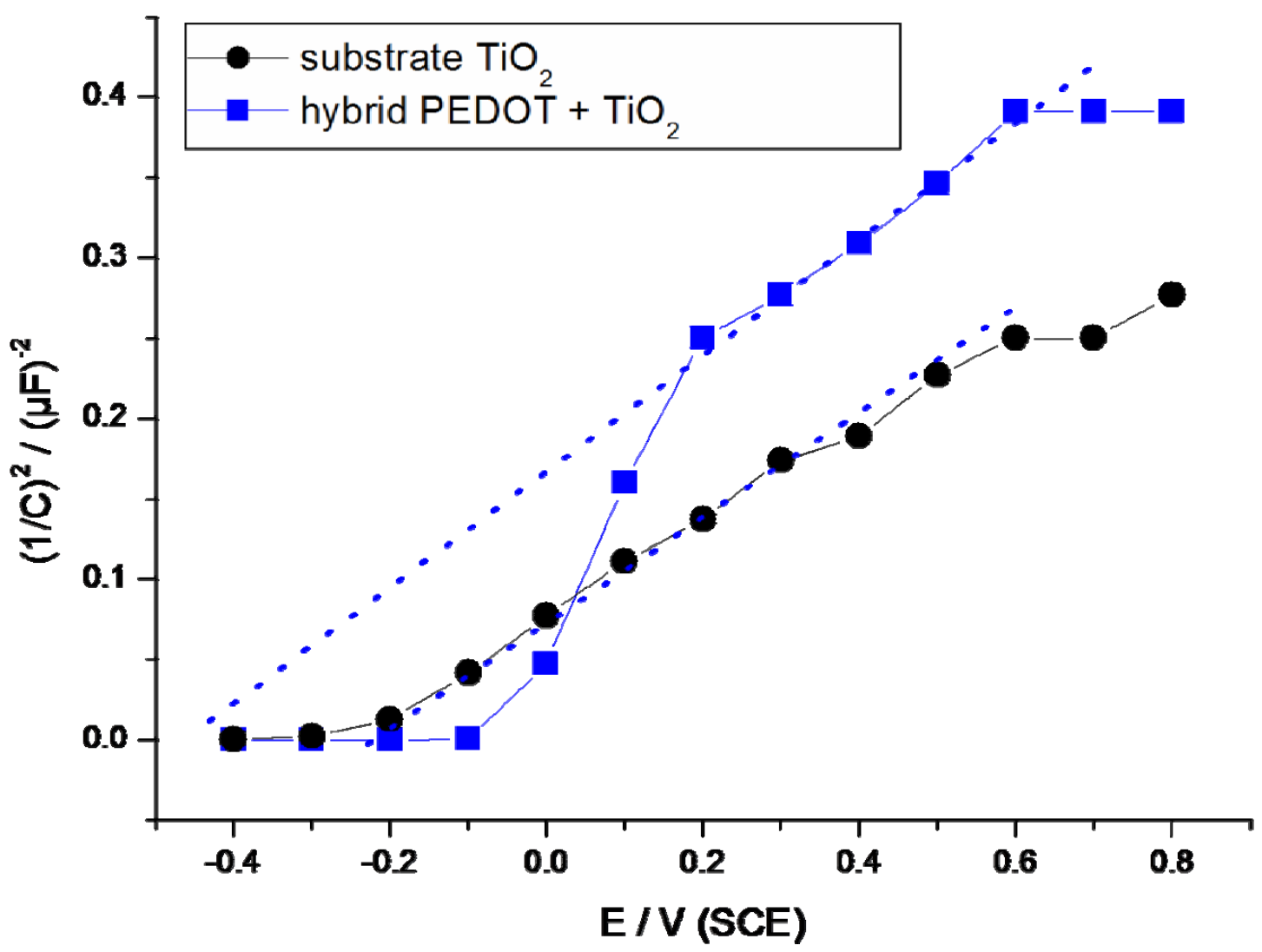

Figure 9 


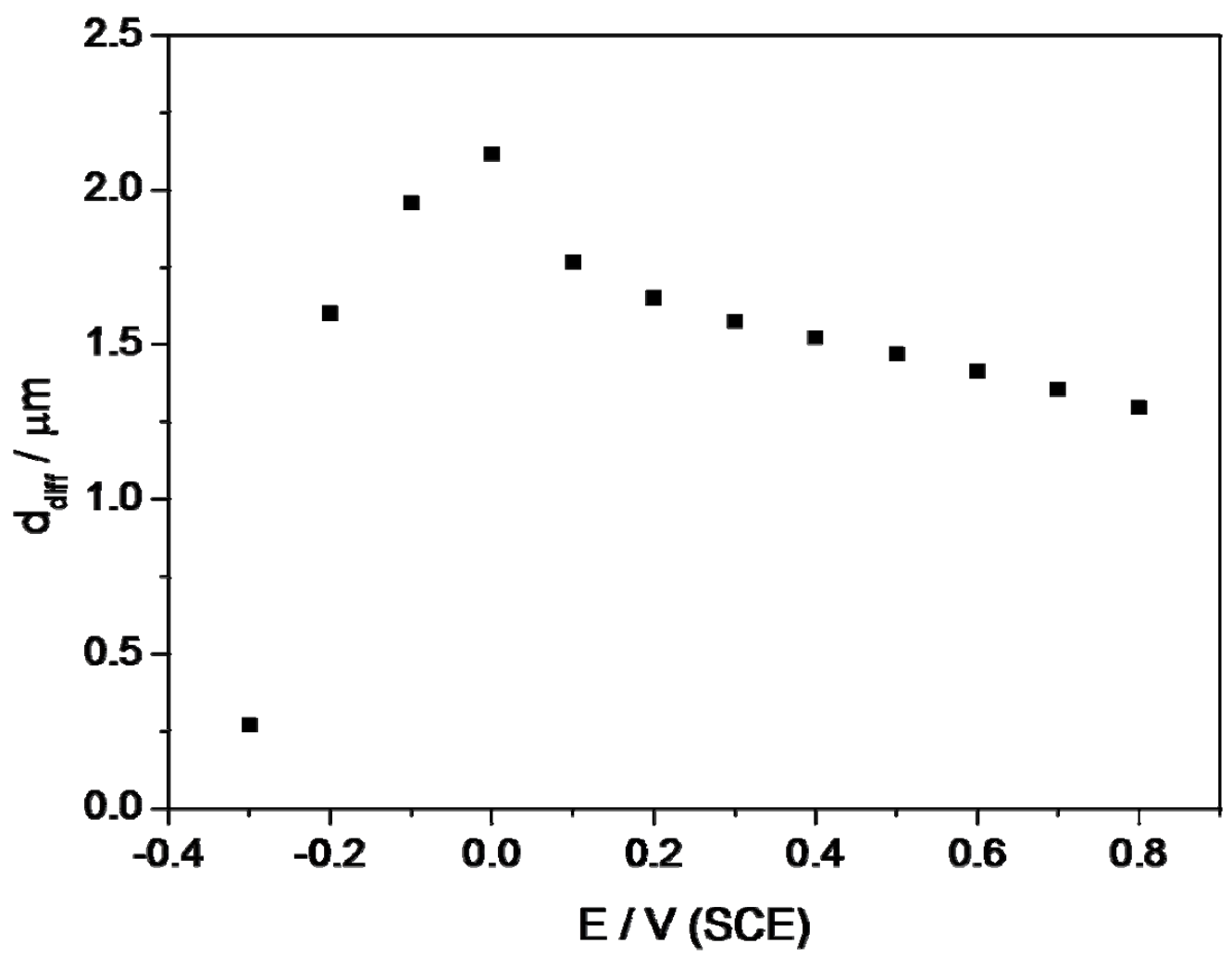

Figure 10 


\begin{tabular}{|c|c|c|c|c|c|c|c|c|c|c|c|c|}
\hline $\begin{array}{l}\text { Pot } \\
\text { V/SCE }\end{array}$ & $\begin{array}{l}\mathbf{R}_{\mathbf{s}} \\
\Omega\end{array}$ & $\begin{array}{l}10^{5} \tau \\
S\end{array}$ & $\begin{array}{l}\mathbf{R}_{\mathbf{i}} \\
\Omega\end{array}$ & $\begin{array}{l}\mathbf{R}_{\mathbf{e}} \\
\mathrm{k} \Omega\end{array}$ & $\begin{array}{l}\mathrm{C}_{\mathrm{i}} \\
\boldsymbol{\mu F}\end{array}$ & $\begin{array}{l}C_{e} \\
\mu F\end{array}$ & $\begin{array}{l}\mathbf{R}_{\mathbf{p}} \\
\Omega\end{array}$ & $\begin{array}{l}\mathbf{R}_{\text {sc }} \\
\mathbf{k} \Omega\end{array}$ & $\begin{array}{l}\mathrm{C}_{\mathrm{sc}} \\
\boldsymbol{\mu F}\end{array}$ & $\begin{array}{l}\mathbf{R}_{\mathrm{ad}} \\
\mathrm{k} \Omega\end{array}$ & $\begin{array}{l}10^{5} R_{p} d \\
\Omega \mathrm{cm}^{2} / \mathrm{s}\end{array}$ & S.D. \\
\hline 0.5 & $116 \pm 2$ & $1.0 \pm 0.1$ & $820 \pm 250$ & $70 \pm 20$ & $15 \pm 0.8$ & $8.3 \pm 0.5$ & $\left(10^{-10)}\right.$ & $37.4 \pm 2.3$ & $3.0 \pm 0.8$ & $22.5 \pm 3.1$ & $2.0 \pm 0.1$ & 0.80 \\
\hline 0.3 & $116 \pm 2$ & $2.0 \pm 0.2$ & $500 \pm 150$ & $59 \pm 18$ & $19 \pm 1.0$ & $12.5 \pm 0.7$ & $\left(10^{-10}\right)$ & $29.6 \pm 1.9$ & $5.3 \pm 1.4$ & $13.8 \pm 1.9$ & $2.0 \pm 0.1$ & 0.81 \\
\hline 0.1 & $116 \pm 2$ & $3.0 \pm 0.3$ & $650 \pm 200$ & $72 \pm 21$ & $36 \pm 1.9$ & $19 \pm 1.1$ & $\left(10^{-10}\right)$ & $22.4 \pm 1.3$ & $13 \pm 3.4$ & $15.8 \pm 2.2$ & $2.0 \pm 0.1$ & 0.81 \\
\hline-0.1 & $116 \pm 2$ & $7.0 \pm 0.3$ & $371 \pm 10$ & $45 \pm 9$ & $66 \pm 1.3$ & $27 \pm 2.4$ & $\left(10^{-10}\right)$ & $4.3 \pm 0.5$ & $35 \pm 4.4$ & $7.4 \pm 0.5$ & $2.0 \pm 0.1$ & 0.59 \\
\hline-0.3 & $116 \pm 2$ & $400 \pm 20$ & $2100 \pm 70$ & $114 \pm 22$ & $103 \pm 2$ & $246 \pm 22$ & $\left(10^{-10}\right)$ & $4.3 \pm 0.5$ & $212 \pm 26$ & $1.6 \pm 0.1$ & $7.0 \pm 0.3$ & 0.48 \\
\hline-0.5 & $116 \pm 2$ & $280 \pm 15$ & $1160 \pm 40$ & $235 \pm 40$ & $186 \pm 4$ & $207 \pm 18$ & $\left(10^{-10}\right)$ & $4.2 \pm 0.5$ & $228 \pm 28$ & $0.35 \pm 0.03$ & $7.0 \pm 0.3$ & 0.36 \\
\hline
\end{tabular}

Table 1: Adjusted parameters at some potential values (taking $\mathrm{Di}\left(\mathrm{Na}^{+}\right)=1.510^{-6} \mathrm{~cm}^{2} \mathrm{~s}^{-1}$ according to reference [14]) for the hybrid structure PPy- $\mathrm{TiO}_{2}$ obtained in SDBS under UV. Fitting procedure follows scheme (b) of Fig. 2

\begin{tabular}{|c|c|c|c|c|c|c|c|c|c|c|c|c|}
\hline $\begin{array}{l}\text { Pot } \\
\text { V/SCE }\end{array}$ & $\begin{array}{l}\mathbf{R}_{\mathrm{s}} \\
\Omega\end{array}$ & $\begin{array}{l}10^{4} \tau \\
s\end{array}$ & $\begin{array}{l}\mathbf{R}_{\mathbf{i}} \\
\mathbf{k} \Omega\end{array}$ & $\begin{array}{l}\mathbf{R}_{\mathbf{e}} \\
\Omega\end{array}$ & $\begin{array}{l}C_{i} \\
\mu F\end{array}$ & $\begin{array}{l}\mathrm{C}_{\mathbf{e}} \\
\boldsymbol{\mu F}\end{array}$ & $\begin{array}{l}\mathbf{R}_{\mathbf{p}} \\
\Omega\end{array}$ & $\begin{array}{l}\mathbf{R}_{\mathrm{sc}} \\
\mathbf{k} \Omega\end{array}$ & $\begin{array}{l}C_{s c} \\
\mu F\end{array}$ & $\begin{array}{l}R_{\text {inf }} \\
k \Omega\end{array}$ & $\begin{array}{l}10^{6} R_{p} d \\
\Omega \mathrm{cm}^{2} / \mathrm{s}\end{array}$ & S.D. \\
\hline 0.5 & $150 \pm 4$ & $9 \pm 2$ & $1.20 \pm 0.20$ & $80 \pm 50$ & $24 \pm 4$ & $61 \pm 20$ & $4.4 \pm 2$ & $1.63 \pm 0.12$ & $32 \pm 2$ & $2.14 \pm 0.3$ & $13 \pm 3$ & 0.74 \\
\hline 0.1 & $150 \pm 4$ & $25 \pm 3$. & $0.95 \pm 0.14$ & $88 \pm 30$ & $50 \pm 4$ & $65 \pm 20$ & $4 . \pm 2.5$ & $2.94 \pm 0.14$ & $43 \pm 2$ & $3.16 \pm 0.50$ & $22 \pm 3$ & 0.72 \\
\hline-0.1 & $151 \pm 3$ & $70 \pm 20$ & $11.8 \pm 6.0$ & $310 \pm 70$ & $160 \pm 13$ & $93 \pm 13$ & $1.2 \pm 4$ & $2.58 \pm 0.15$ & $54 \pm 2.3$ & $7.07 \pm 1.00$ & $53 \pm 11$ & 0.81 \\
\hline-0.3 & $151 \pm 2$ & $1.5 \pm 1$ & $0.54 \pm 0.12$ & $71 \pm 20$ & $128 \pm 10$ & $92 \pm 12$ & $3 \pm 4$ & $1.83 \pm 0.17$ & $152 \pm 8$ & $12.0 \pm 1.4$ & $3.1 \pm 0.2$ & 0.69 \\
\hline-0.5 & $151 \pm 2$ & $1.0 \pm 0.1$ & $0.74 \pm 0.35$ & $61 \pm 30$ & $480 \pm 40$ & $294 \pm 30$ & $0.5 \pm 1$ & $7.23 \pm 3.2$ & $443 \pm 23$ & $39.0 \pm 20$ & $1.2 \pm 0.1$ & 0.68 \\
\hline
\end{tabular}

Table 2: Adjusted parameters at some potential values (taking $\mathrm{Di}=410^{-7} \mathrm{~cm}^{2} \mathrm{~s}^{-1}$ according to reference [14]) for the hybrid structure PPy-TiO obtained in $\mathrm{LiClO}_{4}$ in the dark . Fitting procedure follows scheme (a) of Fig. 2 


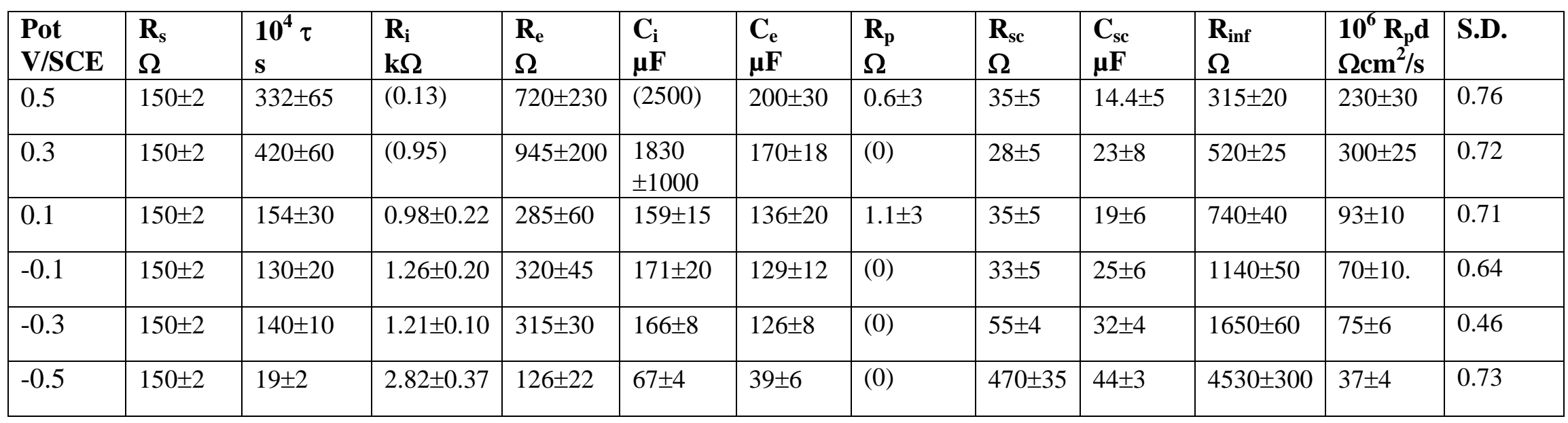

Table 3: Adjusted parameters at some potential values (taking $\mathrm{Di}=410^{-7} \mathrm{~cm}^{2} \mathrm{~s}^{-1}$ according to reference [14]) for the hybrid structure PPy-TiO obtained in $\mathrm{LiClO}_{4}$ under UV light. Fitting procedure follows scheme (a) of Fig. 2

\begin{tabular}{|c|c|c|c|c|c|c|c|c|c|c|c|c|c|}
\hline $\begin{array}{l}\text { Pot } \\
\text { V/SCE }\end{array}$ & $\begin{array}{l}\mathbf{R}_{\mathbf{s}} \\
\Omega\end{array}$ & $\begin{array}{l}\tau \\
\mathbf{s}\end{array}$ & $\begin{array}{l}\mathbf{R}_{\mathbf{i}} \\
\Omega\end{array}$ & $\begin{array}{l}\mathbf{R}_{\mathbf{e}} \\
\Omega\end{array}$ & $\begin{array}{l}C_{i} \\
\mu F\end{array}$ & $\begin{array}{l}\mathrm{C}_{\mathrm{e}} \\
\boldsymbol{\mu F}\end{array}$ & $\begin{array}{l}\mathbf{R}_{\mathbf{p}} \\
\Omega\end{array}$ & $\begin{array}{l}\mathbf{R}_{\text {sc }} \\
\Omega\end{array}$ & $\begin{array}{l}C_{s c} \\
\mu F\end{array}$ & $\begin{array}{l}R_{\text {inf }} \\
\mathbf{k} \Omega\end{array}$ & $\begin{array}{l}10^{6} R_{p} d \\
\Omega \mathrm{cm}^{2} / \mathrm{s}\end{array}$ & S.D. & $\begin{array}{l}\mathrm{C}_{0} \\
\mathrm{mF}\end{array}$ \\
\hline 0.8 & $360 \pm 4$ & $0.20 \pm 0.02$ & $282 \pm 9$ & $85 \pm 7$ & $3.5 \pm 0.3$ & $4.3 \pm 0.8$ & $2.8 \pm 3$ & $44 \pm 5$ & $1.6 \pm 0.5$ & $7.5 \pm 2$ & $5.2 \pm 0.2$ & 0.38 & 1.7 \\
\hline 0.6 & $360 \pm 4$ & $0.24 \pm 0.02$ & $281 \pm 9$ & $85 \pm 7$ & $3.5 \pm 0.3$ & $3.8 \pm 0.6$ & $3.0 \pm 3$ & $36 \pm 5$ & $1.6 \pm 0.5$ & $8.1 \pm 2.1$ & $5.7 \pm 0.2$ & 0.38 & 1.7 \\
\hline 0.4 & $360 \pm 4$ & $0.29 \pm 0.01$ & $271 \pm 8$ & $99 \pm 7$ & $4.3 \pm 0.4$ & $3.9 \pm 0.6$ & $3.4 \pm 3$ & $36 \pm 5$ & $1.8 \pm 0.6$ & $14.4 \pm 5$ & $6.2 \pm 0.2$ & 0.40 & 1.9 \\
\hline 0.2 & $360 \pm 4$ & $0.34 \pm 0.02$ & $271 \pm 10$ & $151 \pm 9$ & $7.1 \pm 0.7$ & $4.5 \pm 0.6$ & $4.6 \pm 3.5$ & $39 \pm 6$ & $2.0 \pm 0.7$ & $14.5 \pm 5$ & $7.6 \pm 0.3$ & 0.44 & 1.7 \\
\hline 0 & $360 \pm 5$ & $0.50 \pm 0.06$ & $391 \pm 25$ & $502 \pm 34$ & $8.7 \pm 0.8$ & $30 \pm 4$ & $6.3 \pm 5$ & $42 \pm 10$ & $4.8 \pm 2.8$ & $15 . \pm 5$ & $17 \pm 1$ & 0.68 & 2.2 \\
\hline
\end{tabular}

Table 4: Adjusted parameters at some potential values (taking Di $=110^{-8} \mathrm{~cm}^{2} \mathrm{~s}^{-1}$ according to reference [38]) for the hybrid structure PEDOT$\mathrm{TiO}_{2}$ obtained in acetonitrile $+\mathrm{LiClO}_{4}$ in the dark. Fitting procedure follows scheme (a) of Fig. 2 